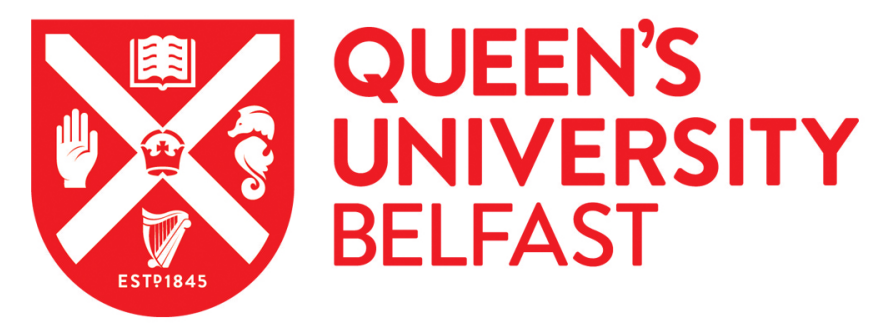

\title{
The Difference Context Makes: Planning and Ethnic Minorities in Northern Ireland
}

Ellis, G. (2001). The Difference Context Makes: Planning and Ethnic Minorities in Northern Ireland. European Planning Studies, 9(3)(3), 339-358. https://doi.org/10.1080/09654310120037612

Published in:
European Planning Studies

Queen's University Belfast - Research Portal:

Link to publication record in Queen's University Belfast Research Portal

\section{General rights}

Copyright for the publications made accessible via the Queen's University Belfast Research Portal is retained by the author(s) and / or other copyright owners and it is a condition of accessing these publications that users recognise and abide by the legal requirements associated with these rights.

Take down policy

The Research Portal is Queen's institutional repository that provides access to Queen's research output. Every effort has been made to ensure that content in the Research Portal does not infringe any person's rights, or applicable UK laws. If you discover content in the Research Portal that you believe breaches copyright or violates any law, please contact openaccess@qub.ac.uk. 
This article was downloaded by:[Queen's University]

On: 5 July 2007

[Queen's University]

Access Details: [subscription number 769796445]

Publisher: Routledge

Informa Ltd Registered in England and Wales Registered Number: 1072954

Registered office: Mortimer House, 37-41 Mortimer Street, London W1T 3JH, UK

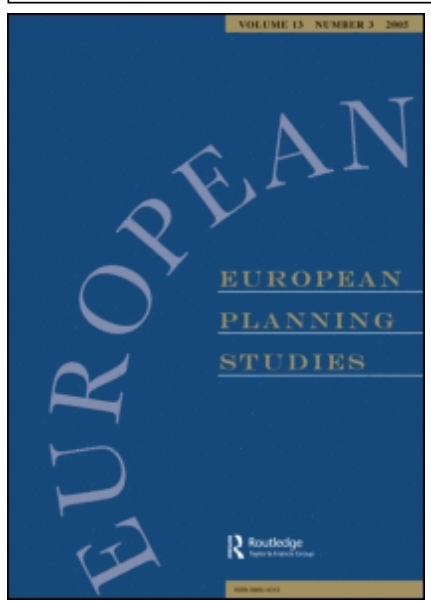

European Planning Studies

Publication details, including instructions for authors and subscription information: http://www.informaworld.com/smpp/title content=t713417253

\section{The Difference Context Makes: Planning and Ethnic} Minorities in Northern Ireland

Geraint Ellis ${ }^{\text {a }}$

a School of Environmental Planning, The Queen's University of Belfast, David Keir Building, Stranmillis Road, Belfast, BT9 5AG, UK..

Online Publication Date: 01 April 2001

To cite this Article: Ellis, Geraint , (2001) 'The Difference Context Makes: Planning and Ethnic Minorities in Northern Ireland', European Planning Studies, 9:3, 339 - 358

To link to this article: DOI: $10.1080 / 713666480$

URL: http://dx.doi.org/10.1080/713666480

\section{PLEASE SCROLL DOWN FOR ARTICLE}

Full terms and conditions of use: http://www.informaworld.com/terms-and-conditions-of-access.pdf

This article maybe used for research, teaching and private study purposes. Any substantial or systematic reproduction, re-distribution, re-selling, loan or sub-licensing, systematic supply or distribution in any form to anyone is expressly forbidden.

The publisher does not give any warranty express or implied or make any representation that the contents will be complete or accurate or up to date. The accuracy of any instructions, formulae and drug doses should be independently verified with primary sources. The publisher shall not be liable for any loss, actions, claims, proceedings, demand or costs or damages whatsoever or howsoever caused arising directly or indirectly in connection with or arising out of the use of this material.

(C) Taylor and Francis 2007 


\title{
The Difference Context Makes: Planning and Ethnic Minorities in Northern Ireland
}

\author{
GERAINT ELLIS \\ [Papter first received, September 1999; in final form, May 2000]
}

\begin{abstract}
The ways the British planning system fosters racial disadvantage and the initiatives taken by local authorities to address such bias have been subject to a number of studies over the last 17 years. This body of research has revealed isolated examples of progressive professional practice within a general pattern of inaction and ignorance. This paper looks at how the needs of ethnic minorities have been accommodated by the planning system in Northern Ireland that has a very different institutional and political context than other parts of the UK. The nature of 'race' relations in Northern Ireland is examined and the concept of 'policy processes' is used to explain why ethnic minorities in the region face similar difficulties to those in Britain. The influence of the political and cultural context is shown to play a key role in framing the policy processes that shape patterns of discrimination. The paper suggests that a full understanding of this context is required if multiculturalism is to be fully accommodated by planning in Europe.
\end{abstract}

\section{Introduction}

The British planning profession has formally recognized the links between land use planning and racial discrimination since 1983 (CRE/RTPI, 1983). In subsequent years a series of reports ${ }^{1}$ have illustrated the continuing difficulties faced by Black and ethnic minorities when dealing with the planning system, highlighting that only a small minority of British planning authorities have made efforts to ensure discriminatory practices are eradicated, while most still display apathy and ignorance towards the needs of their ethnic minority communities. A strong correlation has been established between progressive policy by a planning authority and a higher Black and ethnic minority population. However, the reason why some authorities, or for that matter, some countries, have planning regimes that are more sensitive to the needs of ethnic minorities is not fully understood. The concept of 'policy processes' has been effectively used to identify how Black and ethnic minority groups may be disadvantaged by the British planning system (Thomas \& Krishnarayan, 1994) and this concept will be used here in an attempt to explain why local planning authorities vary in their response to potential issues of discrimination.

Geraint Ellis, School of Environmental Planning, The Queen's University of Belfast, David Keir Building, Stranmillis Road, Belfast, BT9 5AG, UK. Tel: + 44-28-90274370; Fax: + 44-28-90687652; E-mail: g.ellis@qub.ac.uk 
This issue will be explored by examining the situation in Northern Ireland, a region never included in the previous reviews of how UK planning has addressed the needs of ethnic minorities. Northern Ireland has a different pattern of immigration than many parts of Europe and a political dynamic that has led to a distinctive pattern of inter-community relations. The way planning has related to the key political dispute between the Protestant/Unionist and Catholic/Nationalist communities has been subject to an extensive, but no means exhaustive analysis (e.g. Bollens, 1999; Boal, 1996; Neill, 1999), but how it has attempted to accommodate the needs of other ethnic minorities ${ }^{2}$ has been consistently overlooked. This paper addresses that omission by reviewing planning practice in the region and examines whether the different context results in a different approach to accommodating ethnic minority needs. This will contribute to the wider debate on planning and multiculturalism in two ways. First, it establishes, for the first time, how planning in Northern Ireland addresses racial disadvantage and thus allows more robust generalizations about planning across the whole of the UK. Second, the 'unique' case of Northern Ireland helps cast light on why planning authorities across Europe may vary in their sensitivity to the needs of ethnic minorities. To facilitate this, the literature on ethnicity and planning will be briefly reviewed, followed by a discussion of the specific nature of ethnic minorities and racism in Northern Ireland. The paper will then outline the structure of the planning system in Northern Ireland and set out the findings of a review of planning practice in the region. A final section sets out a number of broader implications that arise from the research findings.

\section{Ethnic Minorities and the Planning System}

It is well established that the British planning system tends to disproportionately benefit particular sections of society such as the articulate middle class or property interests (e.g. Reade, 1987). Given the relative disadvantage suffered by members of the Black and ethnic minority population (Skellington and Morris, 1996) it is not surprising that they have not fared as well under the system as other groups. Indeed, Thomas and Krishnarayan (1994) have suggested that the socially conservative nature of planning "creates the likelihood that the racism, and disadvantage justified by it, characterising British Society as a whole will be reproduced within the planning system". The ways in which planning reproduces such disadvantage are well documented (e.g. CRE/RTPI, 1983; Thomas, 1994a; Thomas \& Krishnarayan, 1994), illustrating that by acting in the 'public interest' or by formally adopting a 'colour-blind' approach to promote equality, planning authorities may overlook the needs of different minority groups and indirectly discriminate against them. Thomas and Krishnarayan (1994) have explained how such disadvantage can arise through planning by using the concept of 'policy processes'. In identifying the five different mechanisms ${ }^{3}$ for making planning decisions, they discuss each one according to the relative disadvantage it creates for Black and ethnic groups. One example is in public inquires (i.e. a semi-judicial process) where there is formal equality of those having 'standing', yet ethnic minorities (and other marginalized groups) may face disproportionate disadvantage when compared to, for example, wealthy property interests, as they may lack the necessary resources required to effectively make their case under the 'rules' of such hearings. Another example is via consultation, where some ethnic minority groups may lack some of the attributes, such as fluency in English, to command any real influence.

In a system where there are clear moral, legal and professional obligations to equality of opportunity (Loftman \& Beazley, 1998), it is perplexing that there has not been more widespread action against such disadvantage. This is partly explained by the signals given by national governments with Thomas (1994b) illustrating how the Conservative governments of the 1980s and early 1990s were extremely sceptical of equal opportunity policies and did not 
create a national policy framework to promote racial equality. This was further accentuated by the way in which the 'social considerations' have been sidelined as legitimate planning issues, giving the system de facto colour blindness. Furthermore, the continual emphasis on speeding up the planning system and the transfer of responsibilities from local authorities to other agencies during the Conservative's reign further reduced the ability of Black and ethnic minority groups to express their views on planning matters (Thompson, 1987). The election of the Labour government in 1997 with election pledges of combating social exclusion has held out more hope for addressing the aspirations of ethnic minorities. While the Blair government has been proactive in addressing inequality in some areas of policy (for example, education and the criminal justice system, see Home Office, 1999), this has not been fully expressed within the statutory planning system. The Government's proposed revisions of the planning system (DETR, 1998) suggest that the priorities for the planning system will continue to be those set by the Conservatives, namely efficiency, costs, economic measures and speeding up the decision-making process.

Although some local authorities are making concerted efforts to address race relations (Loftman \& Beazley, 1998), in the absence of strong central guidance, most have been reluctant to recognize the racial dimension to planning and have been unwilling to introduce policies that recognize issues of multiculturalism. Three major reports have attempted to provide a picture of how planning authorities are addressing this issue. In 1983 the RTPI and Commission for Racial Equality jointly produced "Planning for a Multi-Racial Britain" (CRE/RTPI, 1983), the first major investigation into how the planning system accommodates multiculturalism. This revealed a high level of ignorance of the needs of ethnic minorities and a failure to involve them in the planning process. Ten years later, the RTPI commissioned a more extensive report, "Ethnic Minorities and the Planning System" (Krishnarayan \& Thomas, 1993), which identified a small, but steady increase in the number of planning authorities taking action. However, its overall findings were similar to those of the 1983 research, with ethnic minority needs continuing to have a low profile among planning authorities. This issue was further examined by the Local Government Association, whose report "Race, Equality and Planning" (Loftman \& Beazley, 1998) includes a more comprehensive survey of planning practice but draws similarly depressing conclusions, indicating little progress since the RTPI's first initiatives 15 years earlier.

The concern caused by these surveys is amplified in the wake of the landmark Macpherson Report (1999). This reported the conclusions of a public inquiry into the murder of a Black teenager, Stephen Lawrence, finding that racism in the Metropolitan Police had contributed to a failure to prosecute the offenders and resulted in poor treatment of the victim's family. The report highlighted how a series of 'fundamental errors' in the investigation was caused by a combination of professional incompetence, a failure of leadership by senior officers and institutional racism. Macpherson defines 'Institutional racism' as being:

The collective failure of an organisation to provide an appropriate and professional service to people because of their colour, culture, or ethnic origin. It can be seen or detected in processes, attitudes and behaviour which amount to discrimination through unwitting prejudice, ignorance, thoughtlessness and racist stereotyping which disadvantage minority ethnic people. (para 6.34)

This concept has had a major impact on the awareness and understanding of racism in the UK and although the inquiry only found direct evidence of institutional racism in the Police Force, it stressed that there was no place for complacency in any other institution. The report regards such discrimination as being a 'corrosive disease' that persists because of the failure of the organizations to openly recognize and address its existence and causes. It goes on to state that "it is incumbent upon every institution to examine their policies and the outcome 
of their policies and practices to guard against disadvantaging any section of our communities" (para 46.27).

Planning authorities are obviously institutions that need to heed such advice if they are to deliver a service that is equitable to all of society. Yet, experience in Britain suggests that while a few planning authorities have introduced policies that respect cultural pluralism, most fail to recognize the needs of ethnic minorities. The reasons why different authorities treat this issue differently have been linked to the relative size of the local ethnic minority population (Loftman \& Beazley, 1998), but this does not fully explain why there is such a variation. Moreover, such a situation is untenable given that "it is a misconception to associate the race issue with a numerical or proportional size of the local black population. To the person or group experiencing discrimination, it is irrelevant whether or not they are a large or small minority" (RTPI/CRE, 1983, p. 16). Clearly a better understanding why some planning authorities are not sensitive to issues of diversity may lead to the identification of more appropriate mechanisms for overcoming such a situation. To aid this discussion, the situation in Northern Ireland will be examined in some detail.

\section{Ethnic Minorities and Racism in Northern Ireland}

The social disruption and a poor economic climate caused by 'The Troubles' has meant that Northern Ireland has not been an attractive target for immigration, so that the region only has a relatively small ethnic minority population. Indeed the region was once described as being "one of the most homogenous in Western Europe" (Marger, 1989a, p. 203). Those minority groups that do have a presence in Northern Ireland have, until recently, been almost invisible, as the political agenda has been dominated by sectarian issues. The census in Northern Ireland has never collected data on ethnic background (but will do so in 2001), so there is some dispute over the actual proportion of the population that would classify themselves as being members of an ethnic minority. A number of assessments have been undertaken, putting the number between 15,000 and 26,000 (Irwin \& Dunn, 1996; McVeigh, 1997; NICEM, 1999). Table 1 shows the most recent estimate, suggesting that they compose around $1.1 \%$ of the population, a little less than Wales and Scotland.

The relatively small numbers hide the fact that the ethnic minority population of Northern Ireland is a highly differentiated one, but with four main groups. The largest community is Chinese, who began to arrive in Northern Ireland from the 1960s onwards, mostly from the rural area of Hong Kong (Watson \& Knight, 1997). The community is economically specialized, almost all working in the catering industry, with a thriving network of small business spread across the region. The second largest group, Travellers have been part of Irish society for centuries. There has been a continuity in the way Traveller society is organized, with the main features being nomadism, self-employment, flexibility, a cash economy and the dominance of extended family groups (Molloy, 1988). A number of socio-economic trends, particularly urbanization, have had a fundamental and detrimental impact on the lives of Travellers, who have high unemployment, low educational attainment and extremely poor living conditions (Irwin \& Dunn, 1996). As the third largest group, the Indian community has had a presence in Northern Ireland for over 60 years, with most of the original settlers coming from Northern India (Punjab and Gujarat). Indians are regarded as one of the more prosperous sections of the population in Northern Ireland, having exploited gaps in the market such as in textile retailing and catering and have become prominent in a number of professions (Irwin, 1997). They have low levels of unemployment and a high degree of educational success. Similarly, the Pakistani population, the fourth largest group, have found relative success in Northern Ireland and display many of the socio-economic characteristics of 
Table 1. Resident population by ethnic group

\begin{tabular}{|c|c|c|c|c|}
\hline & \multicolumn{4}{|c|}{ Percentages } \\
\hline & $\begin{array}{c}\text { Northern } \\
\text { Ireland }\end{array}$ & England & Wales & Scotland \\
\hline White & 98.9 & 93.8 & 98.5 & 98.7 \\
\hline Black $^{\mathrm{a}}$ & 0.1 & 1.9 & 0.2 & 0.3 \\
\hline Indian & 0.1 & 1.8 & 0.2 & 0.2 \\
\hline Pakistani & 0.1 & 1.0 & 0.2 & 0.4 \\
\hline Bangladeshi & - & 0.3 & 0.1 & - \\
\hline Chinese & 0.5 & 0.3 & 0.2 & 0.2 \\
\hline Irish Traveller ${ }^{\mathrm{b}}$ & 0.1 & - & - & - \\
\hline Other groups & 0.2 & 1.0 & 0.4 & 0.3 \\
\hline Total persons $(000 \mathrm{~s}=100 \%)$ & 1,578 & 47,055 & 2,835 & 4,999 \\
\hline
\end{tabular}

Sources: OPCS, 1993 and NICEM, 1999. NICEM figures are estimated on figures supplied by ethnic minority communities in Northern Ireland, with modifications by NICEM based on the last Census figures.

${ }^{a}$ Northern Ireland statistics do not sub-divide the Black population by the categories in the 1991 census in the rest of the UK (African, Caribbean, etc), so these have been amalgamated.

${ }^{b}$ No accurate data exists on the number of Gypsies and Travellers in England, Scotland and Wales, although recent research by the Centre de Recherches Tsiganes suggests the UK population could be as high as 120,000 .

the Indian community and tend to be employed in the clothing, grocery or catering business (Donnan \& O’Brien, 1997).

The development of the peace process from the early 1990s onwards has fundamentally changed the nature of political debate in the region, with issues of cultural pluralism and racial equality appearing on the policy agenda for the first time. The emerging visibility of minority cultures within this climate has benefited from the efficacious mobilization of groups representing ethnic communities, particularly the Chinese Welfare Association (CWA) and the Northern Ireland Council for Ethnic Minorities (NICEM). These organizations have been effective in drawing attention to the presence of cultures beyond the Catholic/Protestant and Nationalist/Unionist divide and highlighted the forms of discrimination experienced by ethnic minorities in Northern Ireland.

The existence of, and demands for rights for, these distinctive communities has not sat well with the traditional green and orange bifurcation of Northern Irish society, itself highly segregated with more than $60 \%$ of the population living in areas that have more than $80 \%$ of one religion. This residential polarization is accompanied by segregation in other areas of life such as education, religious practice, business, voluntary organization and even in the newspapers read. With every outbreak of violence there has been a 'ratcheting' up of segregation (Boal, 1999) so that it may only be through shopping in the major retail outlets or work that many members of the two main communities interact. Even then overt group differences are maintained by 'social cues and symbols' (Marger, 1989a, p. 60).

The pattern of group identities and antagonisms in Northern Ireland clearly has a complex basis linked to the cultural and political legacy of the British presence in Ireland (Brewer, 1992). The relationship between ethnic minorities and the White Catholic and Protestant communities is a tortuous one (see Hainsworth, 1998) where racial discrimination has been subordinated to inequalities based on religion. The links between sectarianism and racism is therefore of relevance in understanding the experience of ethnic minority groups in the region. 


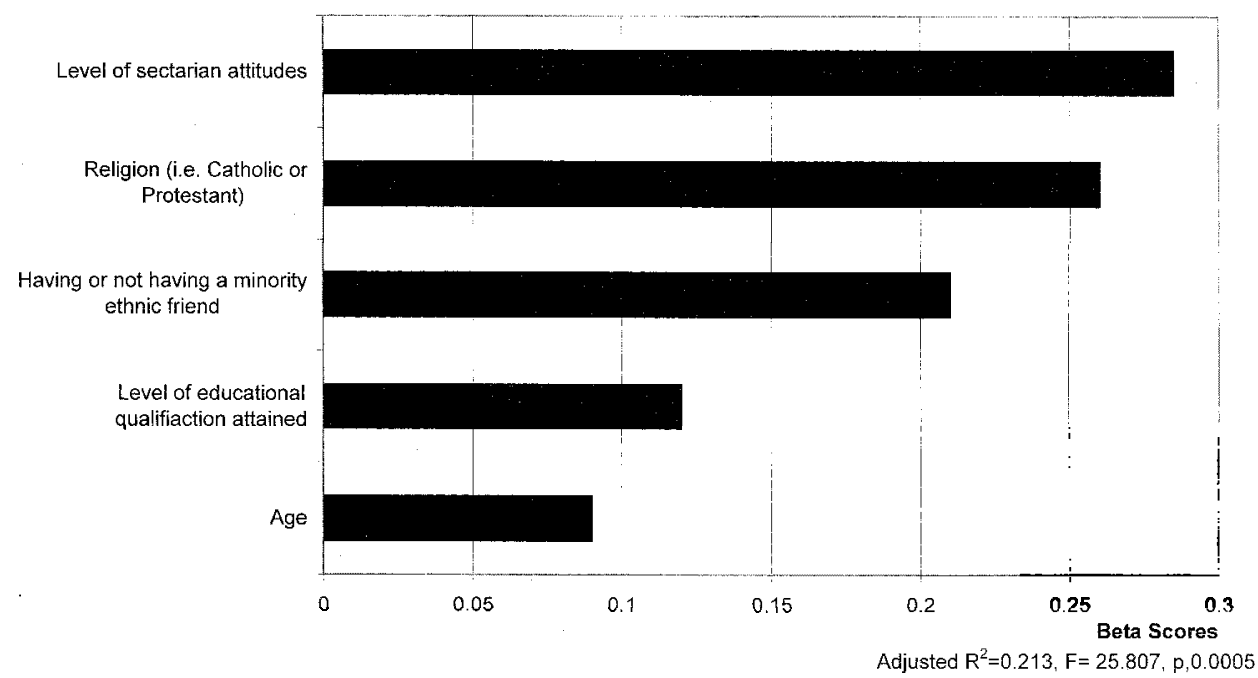

Figure 1. Relative influence of factors on levels of racial prejudice (Connolly \& Keenan, 2000, p. 34).

Sectarianism can be defined as "the determination of actions, attitudes and practices by beliefs about religious difference, which results in their being invoked as the boundary marker to represent social stratification and conflict" (Brewer, 1992 pp. 258-259). Although sectarianism is not so well theorized as racism, both concepts can be seen to have similarities in that religion is evoked in a similar way to that of 'race' as a means of representing other inequalities and conflicts. Clearly there are differences in that sectarianism views group differences based on socialization and learning (e.g. taking cues from area of residence, language use and cultural symbols such as flags), while racism recognizes differences in physical appearance. Other critical differences between sectarianism and racism is that the social mark evoked in sectarianism can be concealed or discarded to avoid the discrimination associated with a particular group, whereas the markers associated with 'race' are unavoidable. Furthermore, and perhaps critically for other ethnic minorities, unlike other racist situations where discrimination tends to be unilateral and emanates from a dominant group, sectarianism has to some degree been propagated by both sides. Brewer (1992) therefore suggests that because of the "simple bifurcation into two denominations, self-definitions of 'us' automatically contain and presuppose a sense of 'them': everyone who is not Protestant is by definition Catholic". This has clearly reinforced the outsider feelings of ethnic minorities in Northern Ireland (Donnan \& O'Brien, 1997) and deterred their engagement in politics in fear of being seen to 'take sides'.

There is clearly a complicated link between sectarianism and racism, with the former interacting and structuring the latter. There are cases of a direct linkage between sectarian behaviour and racism, such as the cooperation between Loyalists paramilitaries and British fascist groups (McVeigh, 1998). Although there may be an unexplored link between Nationalist sectarianism and racism, surveys have found that Nationalists tended to be more tolerant to ethnic minorities than individuals who have a closer identification with Britain (Brewer \& Dowds, 1996, p. 108; Connolly \& Keenan, 2000, p. 28). Indeed Connolly and Keenan (2000, p. 34) found that of all the factors influencing levels of racial prejudice, sectarian attitudes and religious identify were the two most important (Figure 1).

Despite the widespread denial of the existence of racism in Northern Ireland (McVeigh, 1998), there is now startling evidence to suggest that racism is far more important in influencing people's initial attitudes towards one another than sectarianism. Connolly and 


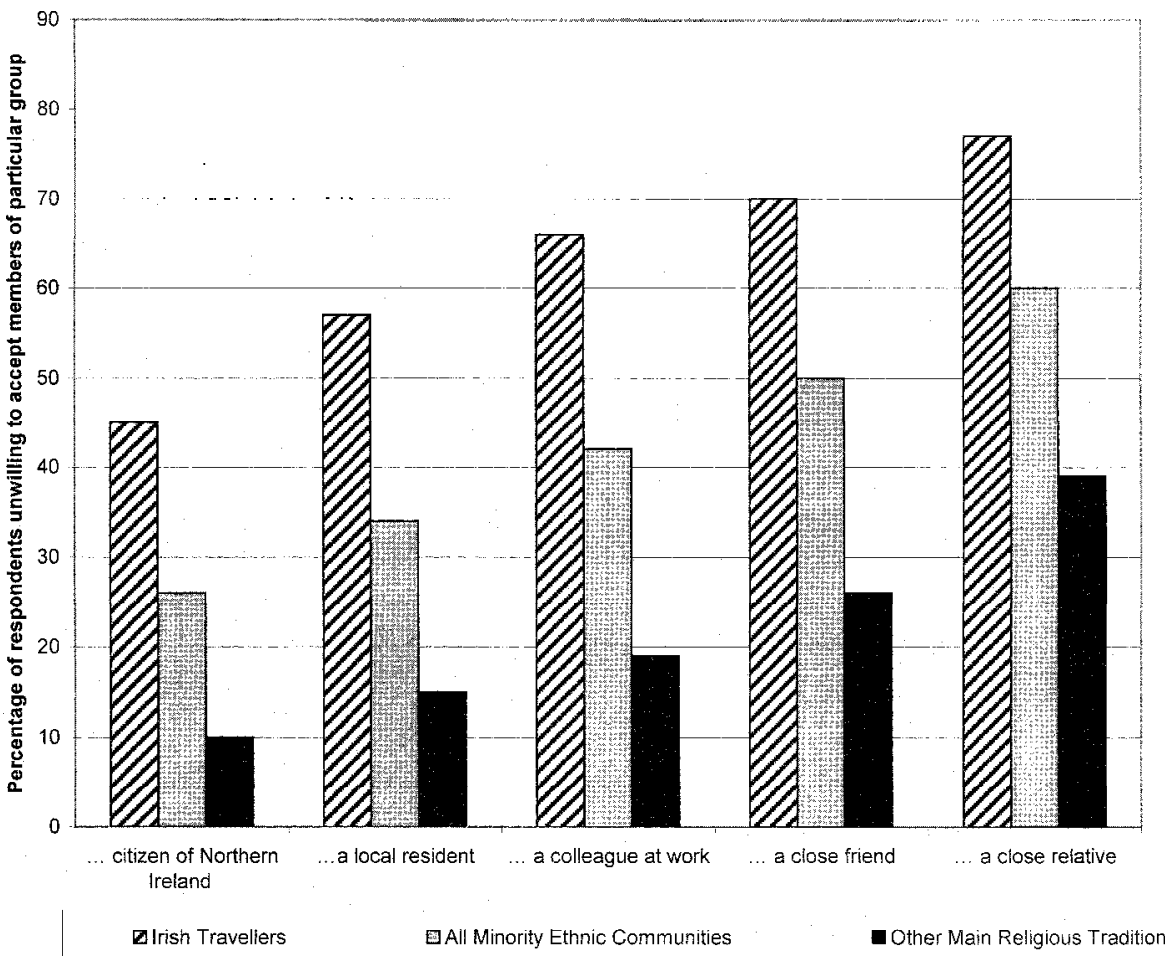

Figure 2. Percentage of respondents unwilling to accept minority ethnic people compared to their unwillingness to accept those of other main religious tradition (Connolly \& Keenan, 2000, p. 18-22).

Keenan (2000) found that double the number of people in Northern Ireland are unwilling to mix with members of ethnic minority groups than they would with those from the other main religious tradition (Figure 2). It is sobering to consider that given the bitter consequences of sectarianism in Northern Ireland, someone is twice as likely to be discriminated on the basis of 'race' than religion.

McVeigh (1992) has argued that although Irish people experience a high level of anti-Irish behaviour, they are racist themselves. Indeed, Brewer and Dowds, (1996) found that attitudes to ethnic minorities in Northern Ireland tended to have many similarities to that in Great Britain, although people in Northern Ireland are less likely to have experiential contact with ethnic minorities, leading to key differences in terms of the perception of the levels of prejudice and attitudes to immigration. McVeigh, (1992) argues that racism in Ireland is different from its manifestation in Britain and elsewhere, quoting a number of interacting processes that account for the "specificity of Irish racism". The first is the link with sectarianism, discussed above. Second is the diffusion of racism from Britain, with racial prejudice being imported via the popular culture it shares with the rest of the UK. The third element of Irish racism is the fact that both religious traditions have participated in, and imported imperialist ideologies. The evidence of Northern Protestant involvement in the British Empire is seen across Belfast, which is still "patheticaly littered with relics of imperialist iconography degrading and exoticing other colonised peoples" (McVeigh, 1992, p. 36) and it is salient that Enoch Powell settled with ease into the Ulster Unionist Party after being exiled from the Conservative Party in the 1960s. The activities of the Irish Catholic church overseas has also encouraged anti-Black racism, encouraging a view of these people as being helpless and passive, needing to be saved by its 
missionaries. The creation of more settled Irish communities in British colonies also assumed racist relationships with indigenous peoples and led to the repatriation of such attitudes. McVeigh (1992, p. 38) quotes the example of Irish Americans, who at the beginning of "The Troubles" were also faced with the issue of "desegregation" in New England, giving rise to the ignominious slogan "Brits out of Ireland, niggers out of Boston". The final element of Irish racism, and one with an acute relevance to land use planning, is its indigenous Anti-Traveller racism. This is not based on colonial domination or imperial justification, but on "sedentarism", where Travelling people have come to represent the symbolic "other". There appears to be far greater levels of preudice against Travellers than any other ethnic group (Figure 2), with a recent survey suggesting that $40 \%$ of people in Northern Ireland believe that the Travellers' nomadic lifestyle was invalid and should not be supported by the Government and $57 \%$ are unwilling to accept Travellers in their local area (Connolly \& Keenan, 2000). McVeigh (1992, p. 41) has suggested this anti-Traveller sentiment originates from the strength of community in Ireland and the problems this causes for outsiders, reinforced by sectarian conflict and social closure. This issue highlights the fact that Irish racism is not purely an importation of British imperialist ideology, but also developed from the specific forms of social relations in Ireland. This also reflects the complicated relationship between sectarianism and racism as Protestants appear to have higher levels of prejudice against Travellers, partly because they are perceived as being Catholic, while Catholic communities tend to have the greatest level of contact with them as they tend to gravitate to Catholic areas (Brewer \& Dowds, 1996, p. 109).

Whatever the nature of racism in Northern Ireland, high proportions of the region's ethnic minorities appear to have experienced discriminatory behaviour with 44\% experiencing verbal abuse, $29 \%$ suffering damage to their property and $10 \%$ being physically abused (Irwin \& Dunn, 1996, p. 101). The RUC have been monitoring the incidence of racially motivated crime since 1996 when 40 incidents were recorded which rose to 106 in 1998. ${ }^{4}$ Hainsworth (1998) includes a number of contributions that highlight experience of discrimination by ethnic minorities, including that of the Chinese community which is routinely abused in the workplace, home, shops, schools and by the police themselves (Watson \& Knight, 1997). Mann-Kler (1997) shows how Northern Ireland's ethnic minorities suffer from indirect discrimination in the provision of a range of public services, while Molloy (1998) and Noonan (1998) record the specific harassment encountered by the Travelling community.

It is important however not to overemphasize a 'uniqueness' of the nature of racism in Northern Ireland, since that denies the common pain felt by ethnic minorities in the region and discards the relevance of anti-racist struggles elsewhere. What makes Northern Ireland different from other parts of Europe is the way in which the region's ethnic minorities have been able to respond to the broader political circumstances and how the hegemony of the sectarian conflict has created or denied opportunities for addressing ethnic equality issues. As such, the attitudes to 'race' described above have taken place against a political backdrop that "allows public representatives, opinion makers, policy developers and sections of the general public to ignore the other fault lines along which discrimination and exclusion take place beyond the pale of mainstream politics" (O'Brion, 1997, p. 54). The best example of this is that the British Race Relations Act (1976) was not extended to Northern Ireland for 21 years, when the Race Relations Order (NI) 1997 was introduced. This created a similar legislative context for ethnic minorities as the 1976 Act and established a Commission for Race Relations for Northern Ireland (CRE(NI)). There are a number of key differences from the legislation in Great Britain (White, 1997), which are relevant to the discussion of 'race' initiatives in planning. These include a specific incorporation of Travellers as an ethnic minority and wider exemptions for the purposes of safeguarding national security, protecting 
public safety or public order. Significantly, the amendment to the British 1976 Act brought by section 5 of the Housing and Planning Act 1986, which ensured that the 1976 Act applied to the planning process in Britain was not replicated in the NI Order. It is therefore unclear whether planning is a service of a public authority for the purposes of the law in Northern Ireland.

Compared to other part of the UK and Europe, Northern Ireland therefore presents a very different context for the struggle for racial equality. To fully understand how the planning system in the region has addressed these issues, a brief explanation is also needed of how it is structured and responded to the region's broader political circumstances.

\section{Planning in Northern Ireland}

The planning system in Northern Ireland is broadly similar to that of the rest of the UK, but with a number of differences (Trimbos, 1997) that significantly influence how the needs of ethnic minority groups are taken into account. The most fundamental difference is that between 1972 and 1999, in an attempt to stabilize the volatile political situation, all political power was transferred from a devolved regional assembly to Westminster. ${ }^{5}$ This has meant that all planning responsibility has been centralized with the Department of the Environment $(\mathrm{NI}){ }^{6}$ with local authorities only having a consultative role. Since 1996 all administrative planning functions have been the responsibility of the Planning Service, set up as a separate cost centre (Planning Service, 1996). Development control decisions are made, following consultation, by an internal board composed of professional officers. Public enquiries and planning appeals are heard before the independent Planning Appeals Commission (PAC). Being separate from the British system means that planning operates under different legislation in Northern Ireland, with the main enabling legislation being the Planning (NI) Order 1991.

Northern Ireland's planners have been faced with the arduous task of maintaining a normal regulatory planning function in extremely difficult circumstances. Not only has the legitimacy of any State intervention been questioned by a large proportion of the Nationalist community, but the 'Troubles' have created a society polarized along sectarian lines that has resulted in specific planning related issues of social and economic deprivation, distorted land markets, blighted space and the need for duplication of many urban services (Boal, 1996). The planning system has responded to such difficulties by becoming heavily technocratic and taken the notion of a unitary 'public interest' as its guiding light. The Planning Service has formally distanced itself from any involvement in politics and until recently has even refused to openly acknowledge the divided nature of society (Neill, 1998), while the increasing polyethnic nature of society is still not appreciated in its policy documents.

The centralization of planning responsibilities has been geared to eradicating sectarianism in policy-making, although the institutional arrangements have, ironically, made it much more difficult to develop a more progressive, culturally inclusive approach to planning. Because day-to-day planning decisions have been effectively isolated from the arena of formal politics, ethnic minorities (and other interests) have been precluded from influencing planning at the local level. However, given the dominance of the green/orange dichotomy of political discourse, it has been difficult for ethnic minority groups to make a positive impact on a local political scene that has shown little sympathy and in many cases outright antagonism to ethnic minorities, ${ }^{7}$ particularly Travellers (see Noonan, 1998). The present system therefore limits the unfavourable interference from local politicians, but relies on a very conservative and technocratic service to promote ethnic minority needs. ${ }^{8}$ The outcome of such a situation is discussed later.

It has been suggested that well-intentioned policies aimed to overcome sectarian division 
in many areas of service provision, such as education and health (Mason, 1998; Mann-Kler, 1997) have worked against ethnic minorities by providing a single 'colour-blind' standard of service that undermines the recognition of pluralistic requirements. One would expect this also to be the case with planning, and the next section sets out how it has accommodated the needs of the region's ethnic minorities.

\section{Ethnic Minorities and Planning in Northern Ireland}

In order to establish the extent to which planning in Northern Ireland is open to the needs of ethnic minorities, an initial scoping exercise was undertaken involving interviews with key representative groups, ${ }^{9}$ followed by an in-depth review of planning practice in the region. To maximize issues of comparability with previous studies this focussed on issues covered by the most recent and comprehensive survey undertaken by the Local Government Association (LGA) in other parts of the UK (Loftman \& Beazley, 1998). In order to adapt to differences in the administrative structure of Northern Ireland, two separate surveys were undertaken. The first reviewed the activities and policies of the Planning Service via structured interviews with senior staff and the second consisted of a postal survey of the 26 District Councils to establish how the local political sphere took into account multiculturalism in relation to planning issues. Further enquires were also made to other parties with an interest in the implementation of the planning system in Northern Ireland, namely the RTPI and the Planning Appeals Commission. The findings of this research have been reported in some detail elsewhere (Ellis, 2000a), so that only the key findings will be reported here, under a number of key themes.

\subsection{Corporate Equal Opportunities and Recruitment}

Every planner in Northern Ireland works in an equal opportunities environment as all public sector planners are employed by the Planning Service and thus covered by the corporate policy of the Northern Ireland Civil Service (NICS). This equal opportunities policy is poorly linked to the delivery of the planning system, a similar situation to the one found by Loftman and Beazley (1998) in the rest of the UK. There is no specific implementation plan for the policy and the Planning Service itself does not have an equal opportunities advisor but uses the resources of a unit that covers all the Department of the Environment. NICS does not monitor the ethnic background of job applicants or its workforce.

\subsection{Development Plans, Planning Policy Guidelines and Practice}

While the UK Government has been reticent in encouraging local planning authorities to specifically recognize ethnic minority needs in statutory plans, such policies can be important in highlighting the potential for indirect discrimination, maintaining consistency in how applications are handled and help secure community facilities. Indeed, Munt (1991) provides evidence that the needs of ethnic minorities are more effectively met if explicitly recognized in planning policies, an approach recommended by the LGA. However, the lack of government guidance has influenced the content of plans, with Loftman and Beazley (1998) finding that only $13 \%$ of authorities in Britain had development plan policies specifically related to the needs of ethnic minorities. Those authorities with relatively large ethnic minority populations were almost five times more likely to have such policies than other authorities. This pattern is reflected in the situation in Northern Ireland with its relatively small ethnic minority population, where there are no policies at any tier of the planning system aimed at meeting their specific needs (excluding Travellers, which are discussed below). The Planning Service 
does not provide guidance on other issues that support the needs of ethnic minorities, such as places of worship (a potentially sensitive issue in Northern Ireland), housing and community facilities. ${ }^{10}$

The absence of such policies suggests that the Planning Service is not sensitive to the differences in the use of land arising from ethnicity or the potential difficulties of ethnic minority groups may face when dealing with the planning system. Indeed, the two main reasons given by the Planning Service for non-inclusion of ethnic minority policies reflect this insensitivity. First it was 'not seen as an issue' and second, it was suggested that "needs were covered by other 'generic' policies". These findings coincide with those of the LGA survey where the first of these reasons was identified by $75 \%$ of planning authorities without such policies, and the second reason by $35 \%$ (see Loftman \& Beazley, 1998).

One exception to this absence of specific policies is the issue of accommodation for Travellers, which were not covered by the LGA survey, but are regarded as a key ethnic group in Northern Ireland. Travellers are included in strategic planning policy for housing (see DoE(NI), 1998, p. 46) and in a number of the local area plans. While most of the local plans have polices that are vague and insubstantial, at least one has conceded that the need for a serviced site for Travellers is a material consideration in evaluating objections to a development plan policy. There is currently no monitoring in Northern Ireland of how different planning polices may impact on different social groups.

\subsection{Development Control}

Development control is an area where the impact of indirect discrimination arising from bureaucratic procedures and insensitive planning policies can become apparent, as well as being a conduit for direct prejudice expressed as racist objections to planning applications. A number of studies have shown how members of ethnic minority groups have significantly higher refusal rates for planning applications than the rest of society (e.g. Thomas, 1994a), suggesting the possible presence of discrimination. The links between planning decisions and the needs of ethnic minority groups are, however, infrequently recognized as Loftman and Beazley (1998) found only $8 \%$ of local planning authorities able to identify planning decisions taken in the previous 12 months where policy considerations related to ethnic minority groups were an issue. The Planning Service in Northern Ireland could identify two current planning applications (both concerning a single proposal to develop a Traveller site) as the only applications having any material or policy considerations to the needs of ethnic minorities. The Planning Appeals Commission also identified two planning appeal decisions dating from 1993 and 1996 where the needs of Travellers were seen as a material consideration. Despite a high level of development activity for catering outlets by the Chinese community there appears to be no openness to the fact that they may face specific issues in making such applications and it was stressed that these were considered purely on 'technical' grounds.

The monitoring of the differential impact of planning decisions is seen by all previous reports as being critical in identifying whether the planning system is prejudicing certain groups and helps identify the action needed to rectify such a situation. Despite strong recommendations in previous reports for the introduction of monitoring, Loftman and Beazley found that only $7 \%$ of local planning authorities monitored applications or decisions. No monitoring is undertaken in Northern Ireland, nor any research undertaken on the planning needs of different ethnic minority groups. It is therefore unclear whether different ethnic groups face particular difficulties in dealing with the development control system and is an area in which more research is clearly needed.

The Planning Service does not have any formal guidelines for dealing with racist representations to planning applications (compared to $20 \%$ in England, Scotland and Wales), 
despite the publication of RTPI guidance on the issue (RTPI, 1996). However, it was suggested by a senior Planning Service officer that because of the history of equality measures aimed at overcoming sectarianism in all areas of Government policy, there was a professional culture sensitized to the potential for discrimination and therefore a neutral stance was taken on every issue. It was suggested that should any objection be based on racism, only 'legitimate planning matters' would be considered when deciding the application. The Planning Appeals Commission also has no policy on racist representations and because of its semi-judicial role, it states it has to reproduce all representations, racist or otherwise.

\subsection{Consultation and Communication}

The above review of planning policy and development control would suggest that ethnic minorities have not been extensively engaged in the planning system in Northern Ireland. One reason for this is the consultation methods used by both the Planning Service and via the District Councils who are empowered to consult with their electorate and submit views to the Planning Service on their behalf.

The Planning Service has a standard system for consultation on planning policy that involves widespread publication in local newspapers and circulation of proposals to parties of recognized interest, such as statutory agencies. Consultation on planning applications involves notices in local newspapers and writing to affected neighbours and to the relevant District Council. There is no standard informal or formal mechanisms for specifically consulting with ethnic minority groups and these groups are not usually targeted for consultation. The Planning Service does stress, however, that it is open to comments from all groups, but does not proactively seek them from any specific section of society. Loftman and Beazley (1998) found that $14 \%$ of local planning authorities had formal mechanisms for consulting specifically with ethnic minority groups and $22 \%$ had informal mechanisms.

It is recognized however that a great deal of effort has been placed on generating views from all sections of Northern Irish society for the Draft Regional Framework (Shaping Our Future) and a consortium of academic and community organizations were employed to manage the consultation process (see McEldowney et al., 1997). Despite a genuine attempt to reach communities not usually involved in planning, debate has tended to focus on territorial struggles related to the sectarian conflict (for example the strategic dominance of the Unionist east over the Nationalist west) and not opened up opportunities to discuss issues of greater significance to other communities. As a consequence, a number of groups representing ethnic minorities participated in the consultation, but none felt it appropriate to submit written comments.

Neither the Planning Service nor the Planning Appeals Commission has a policy of translating any documents into other languages (compared to $27 \%$ of local planning authorities in the LGA survey). However, both state that they would provide interpreters at hearings and meetings if requested, but stress that there is little demand for such facilities as there has only ever been a few requests, all for Irish translations.

\subsection{Local Authorities}

As explained previously, District Councils in Northern Ireland only have a consultative role in planning, so Loftman and Beazley's (1998) survey of local planning authorities could not be directly replicated. However, this consultative role was examined via postal questionnaire sent to the 26 Councils in June 1999, generating a response of $77 \%$. It must be noted that planning is not regarded as a priority area for most of the Councils, with only one of them $5 \%$ of respondents) employing a professional planner and even this is a half-time post. In most cases, 
the Environmental Health Department or Chief Executive's office deals with planning matters. Furthermore, the Councils only employ an average of 1.7 total staff (including professional, technical and administrative personnel) for undertaking their planning duties. None of these staff were identified in the survey as being from an ethnic minority background, although $70 \%$ of the responding Councils had corporate equal opportunities policies.

It must also be appreciated that the District Councils in Northern Ireland do not have responsibility for major areas of expenditure such as housing, education or social services. As a result, ethnic minority groups have tended to focus on Central Government providers of these critical services (see Mann-Kler, 1997), rather than the District Councils. Consequently, the Councils have not tended to be subject to any political lobbying or debate on 'race', thus further reducing their engagement with this issue.

Given this background, it is not surprising that $57 \%$ of the Councils responding to the survey gave one of the two lowest ratings (out of seven) when asked for "the importance the Council places on addressing race/ethnic minority issues in planning". Only $14 \%$ gave one of the two highest rankings. The reasons given for the low rating are also instructive, with $40 \%$ of those giving reasons suggesting it was 'not an issue' and $40 \%$ stating that their planning role was a technical one dealing only with land use or 'planning' matters.

None of the Councils had an equal opportunities policy for responding to planning applications and only one Council $(5 \%)$ noted that any of its employees had designated responsibility for 'ethnic-minority related issues' (in relation to planning): 78\% of Councils had no race awareness or anti-racist training programme for its staff.

The survey found that every Council has responded to at least one policy document issued by the Planning Service in the previous 12 months, but only one Council (5\% of respondents) had mentioned the needs of ethnic minorities in any of its responses. The most common reasons for non-inclusion, by $82 \%$ of Councils, was because ethnic minority needs 'were not an issue'. Only two Councils (12\% of respondents) had responded to any planning application in the previous 12 months where policy considerations in relation to ethnic minorities were an issue, both involving applications related to Travellers.

In terms of responding to planning applications, the survey found that only $59 \%$ of Councils undertake any consultation with their electorate before submitting a response to the Planning Service, and only 19\% claim to undertake any consultation directly with members of any ethnic minority group. Those Councils that did make this claim carried out general consultation (mostly by the councillors being available to be approached on any planning issue), which ethnic minority constituents could take advantage of. No Council suggested they had adopted any consultative mechanism that would help ethnic minorities overcome any specific obstacles they may have in dealing with the Council. Only one Council (5\% of respondents) had a policy for dealing with responses from the public that could be construed as being racist.

The comments made by the Councils in their responses to the questionnaire are also instructive in that most stress that they are committed to implementing equal opportunities policies, but clearly fail to appreciate how this can be applied to planning matters. Many state that they treat all members of the community equally, essentially adopting the "colour-blind" approach much criticized in previous research reports. The activity of one District Council stands out, in that it was the only authority taking a pro-active approach to accommodating the needs of ethnic minorities. This Council had close involvement with the Commission for Racial Equality for Northern Ireland and had a sub-committee dedicated to addressing issues arising from the Traveller community. This Council had notably lobbied the Planning Service to give special consideration to planning applications dealing with ethnic minorities.

\section{Discussion}

The review of Northern Ireland planning practice suggests a level of insensitivity and 
ignorance within the Planning Service and District Councils regarding the potential for ethnically-related disadvantage and the need to acknowledge multiculturalism within land use policy. These findings are disappointing, although not entirely surprising given the conclusions of previous research in England, Scotland and Wales. The situation in Northern Ireland is extremely similar to that found by Loftman and Beazley (1998) in areas with relatively small Black or ethnic minority populations (see also Davies, 1993) and supports the evidence suggesting that there is a strong correlation between the size of the local ethnic minority population and sensitivity of the planning system to their needs. However, merely highlighting this correlation does not alone explain the processes that give rise to such a situation, nor suggest how those planning authorities with relatively low ethnic minority populations can be encouraged to become more sensitive to their needs, that is apart from encouraging a growth in the local ethnic minority population!

Therefore an examination of why Northern Ireland is similar to other regions, despite its significantly different community relations and political context, may provide a broader understanding of how planning on a European scale can become more sensitized to the needs of minority groups. A starting point for this discussion is the concept of 'policy processes' in planning, initially developed by Healey et al. (1988), but used by Thomas and Krishnarayan (1994) in their analysis of the mechanisms by which Black and ethnic minorities are disadvantaged in the British planning system, discussed earlier in the paper. Thomas and Krishnarayan (1994) do acknowledge that policy processes are linked to broader professional, political and ideological currents and that the concept can be used to understand geographic variations in policy (p. 1907). However, as they were primarily concerned with the British planning system, they did not consider in depth how different structural conditions, such as other legislative systems, may alter the form of the policy processes at work. Healey (1990) notes the importance of understanding such a context to the study of policy processes and quotes Hudson (1979), among others, in suggesting this can be defined in terms of a set of factors, such as those governing economic or political circumstances. The review of the situation in Northern Ireland has illustrated that while it shares many of the same policy processes as planning in Britain the context for policy is significantly different. This suggests that it may be helpful to adopt a two-tier interpretation of the capacity of a planning authority to accommodate cultural pluralism.

At one level there are variables that determine the context governing patterns of political power and discourse over ethnicity and 'race'. The next level focuses on the dynamics of the policy processes within the realm of planning itself and is essentially dependent on the power relations described by Thomas and Krishnarayan (1994). There will inevitably be strong patterns of interaction between these two levels, with policy processes reflecting the attributes of their context which may then also help redefine that context (Healey, 1990). A fuller discussion of how this context may affect a planning authority's capacity to adopt ethnic minority sensitive polices will be explained with relevance to the situation in Northern Ireland.

In their comparison of Sweden and Britain, Khakee and Thomas (1995) suggest three factors that determine the differences in approach in the two countries: the history of immigration; the level of political mobilization of ethnic minorities; and the professional planning agenda. While they may have identified the most important factors in determining the proclivity for ethnic pluralism in planning, these factors are unlikely to explain all variations. If a more generic framework for interpreting the context for planning in Europe is to be developed, these factors need to be generalized and extended to cover a wider range of circumstances. This could therefore include:

- Historical factors: Khakee and Thomas (1995) emphasize and draw on the work of Castles and Miller (1993) to suggest that the history of immigration is a key determinant of how a State many tackle issues of ethnicity. Although underpinned by a more complex analysis of social relations, this perspective ultimately suggests that those nations with longer and more 
sustained patterns of immigration (such as Britain) are more likely to have been subject to pressure for anti-discrimination measures, than those that have been subject to less immigration (such as Sweden). This may also assist in explaining variations in attitudes to 'race' at a regional level and applies, to a certain extent, in the case of Northern Ireland. However, as noted earlier in the paper in some regions of Europe, such as Northern Ireland, the dominant population trend may not be one of immigration, but emigration and/or colonialism. These two processes may provide a different dynamic to the racialization of political discourse, although the ultimate effect may be the same. Previously examples were given of how attitudes to multiculturalism in Northern Ireland had been influenced by the repatriation of the racist views of Irish migrants to the New World and how the colonial relationship with Britain had encouraged complicity in imperialism, generated a climate of sectarianism and increased the absorption of racist popular culture. Similarly the process of de-colonization may shape attitudes to race, vividly shown in recent land disputes in Zimbabwe, but also in the formulation of a new political agenda in which multiculturalism may develop, as in South Africa or as currently emerging in Northern Ireland.

- Political factors: The ability of ethnic minorities to mobilize at national and local levels is rightly seen as an essential factor in developing a planning policy that is sensitized to the needs of ethnic minorities (Khakee \& Thomas, 1995; Krishnarayan \& Thomas, 1993) and one that is clearly undeveloped in Northern Ireland. For a number of reasons connected to the broader political situation in the region, ethnic minorities have until recently kept a relatively low profile and not sought political exposure. As a result, there is no ethnic minority representation at District Council, Assembly, MP, MEP or Ministerial level. Furthermore, the social and economic conservatism of the main political parties in the region has fostered a climate where positive discrimination in favour of any section of society has become a sensitive issue and given low political credence (Hainsworth, 1998). When this is combined with the fact that planning is undertaken in the absence of local political pressures experienced by planning authorities in other parts of Europe, the result is a political context in which ethnic minorities have been very tightly constrained with little scope for mobilizing around local issues such as planning. Therefore while the low level of political mobilization of ethnic minorities in Northern Ireland has resulted in the same outcome as that in Sweden or some rural parts of Britain, it is underlain by a very different set of political processes. Further examples of how political ideologies at a national or regional level may control the ability of local planning authorities to address issues of social justice are the constraining influence of Thatcherism, (Thomas, 1994b) or in providing opportunities for inclusion, such as the current situation in Northern Ireland (see later).

- Professional factors: The final key comparative variable identified by Khakee and Thomas (1995) is the agenda of the planning profession, which may lack a multicultural dimension, as in Sweden, or as in the case of Britain, play an important supportive role, particularly in "providing non-local legitimacy for the arguments of those struggling for change at a local level" (Khakee \& Thomas, 1995, p. 507). However, the progressive stance taken by the RTPI at a national level in the UK has not created a situation where all its members lobby for social justice nor where anti-discriminatory practices have a high priority on every local planning agenda. This suggests that the professional commitment to equal opportunities is only operationalized in areas where it finds more local political resonance, either within the regional branch of the institute or in relation to the broader political climate of an area. This is particularly significant in the case of Northern Ireland where, in response to the political conflict of the last 30 years, the planning profession has adopted an extreme position of formal technical neutrality (Blackman, 1991; Boal, 1996; Bollens, 1999), where the divided nature of the society remained unacknowledged (Neill, 1998). The centralization of planning responsibilities in 1972 was a tactic to promote stability and overcome sectarian discrimination, but has left planning politically isolated and professionally domi- 
nated. Therefore basic land use regulation was maintained under difficult and contentious circumstances by resorting to a narrow technical definition of planning's role, supported by the pretence of a definable 'public interest', minimal public participation and domination of engineering-based solutions. While one can debate whether this was an appropriate response to the political circumstances, the hegemony of technocratic neutrality has led to the perception that planning in the region was conspiratorial and insensitive to social needs. Thus, Bollens (1999, p. 268) has suggested that "Neutrality is associated with unequal outcomes, poor public perception, and ineffective upliftment of Belfast's economically deprived". Therefore, in a situation where differences based on majority group differences failed to be acknowledged by the planning system, it is unsurprising that it has not been open to the possibility that other ethnic minority cultures may be systematically discriminated against as a result of certain land use policies. In the case of Northern Ireland, local political circumstances have meant that the equal opportunities agenda of the RTPI has failed to register with the local professional subculture. This suggests that the role of a national professional body may not be conclusive in addressing issues of multiculturalism and there may be a significant 'implementation gap' according to local circumstances, depending on the relationship with local political realities. Thus professional equality aspirations may only achieve full realization under a hegemony of multiculturalism (Quadeer, 1997), where issues of ethnicity are perceived to be a 'problem' needing to be addressed (Loftman \& Beazley, 1998) or where a commitment to equality is an explicit part of a local political programme (GLC, 1985).

The issues identified by Khakee and Thomas (1995) as explaining the main differences between Sweden and Britain therefore offer insights into understanding more general contexts for the way planning is sensitized to multiculturalism, if a wider definition of each factor is taken into account. However, any comprehensive analysis also has to take account of other factors, such as cultural or economic issues. The discussion on the nature of racism in Northern Ireland illustrates how cultural factors may also contribute to the context of planning processes. It was shown that there is a particularly high level of racist attitudes towards Irish Travellers, which McVeigh (1992) suggests is a cultural phenomenon where the strong sense of community has pathologized 'outsiders'. This represents a very different source of racial antagonism to Britain, where it has emerged from a history of colonialism and immigration. Such differences clearly need to be acknowledged if an appropriate anti-racist strategy is to be developed. There are examples of this from Northern Ireland, where Travellers are specifically highlighted in Race Relations legislation and where anti-racist struggles have integrated the defence of Travellers, while in other parts of Europe it remains a marginal issue. Unfortunately, the planning system in Northern Ireland has failed to take full account of the nature of anti-Traveller sentiment and not fully confronted its own role in addressing such discrimination.

Finally, an analysis of the context for planning also needs to take into account economic factors. This can clearly be addressed on a number of levels from locating ethnic minorities in terms of their economic relations and class position (Miles, 1987) or understanding the process of immigration (e.g. Marger, 1989b). Economic factors may also frame policy processes in a very direct way, with Loftman and Beazely (1998) suggesting that the increasing constraint on local authority finance is a key factor in explaining why more local planning authorities have not adopted policies reflecting cultural pluralism. Within Northern Ireland, the fact that the Planning Service has been constituted as a 'Next Steps' agency means that its activities are governed by funding linked to its 'contract' with government (Planning Service, 1996), which stresses quantitative performance targets rather than qualitative goals such as equality.

Together these factors will define the context for those policy processes that determine the influence of ethnic minority groups in planning in any one area. An illustration of how the context may constrain policy-making in planning, is that of the politico-rational process in Northern Ireland. This is the process that is dependent on the "judgement of politicians in the 
formal areas of representative democracy" (Healey et al., 1988, p. 224.) and one in which ethnic minority interests are often sidelined. While suggesting that this realm of politics will not offer a 'quick fix' for addressing racial disadvantage in planning, Thomas and Krishnarayan (1994) suggest "it can be more permeable to black and ethnic minority influence than other processes" (p. 1904). Yet in the case of Northern Ireland the domination of politics by sectarian issues has led to a reluctance of ethnic minority groups to get involved in such debates, effectively making this whole process impermeable to them. Another example from Northern Ireland is that of the techno-rational processes where planners themselves "define issues and interests and hence which groups and values should be considered and how" (Healey et al., 1988, p. 224). In the context of the centralization of planning responsibilities this process has become the most dominant for decision-making, yet the professional agenda developed in response to the 'Troubles' has restricted such activity to technical issues and marginalized any consideration of social justice.

This analysis implies that while the policy process approach helps conceptualize the ways in which racial disadvantage may be generated through the planning system, a clearer understanding of the context for those processed will be required if appropriate initiatives are to be taken to tackle them. Previous research has highlighted a number of broad areas that need to be adopted in any area if planning is to be sensitized to the needs of ethnic minorities, such as monitoring of the impact of planning policy; encouraging more members of ethnic minorities to join the planning profession; and ensuring consultative mechanisms reflect appropriate cultural needs. The discussion of Northern Ireland goes some way to explain why such policies have not been universally adopted and suggests that multicultural initiatives may have to be more closely adapted to local circumstances. In the case of Northern Ireland, the dominance of technocratism, the nature of the planning institutions, the broader political context and the nature of Irish racism need to be reflected in any strategy for sensitizing the planning system to the needs of ethnic minorities. The current peace process is helping to develop such a strategy, as broader initiatives to overcome sectarian inequalities in all areas of government policy are incorporating the issue of racial discrimination through the concept of 'equality schemes' (described in more detail in Ellis, 2000b). In contrast to the localized initiatives found in England, this represents a top-down approach to equality that is appropriate to the situation described for a number of reasons. First, by constituting equality as a new statutory duty, it focuses attention on the dominant processes in public policy in Northern Ireland, namely the techno-rational and bureaucratic-legal. Equality has thus become a material consideration in every administrative decision, an effective tactic to overcome the bureaucratic reluctance described earlier in the paper. Secondly, it has avoided the obstacles of the local political culture by embedding equality in legislation, rather than defining it as a 'policy' subject to local political priorities. While these equality schemes do not guarantee an equitable outcome to every policy, they have ensured that the possibility of disadvantage in the process of policy-making is overtly acknowledged. While the equality schemes on their own will not guarantee the development of a culturally-sensitive approach to planning and requires many initiatives internal to the Planning Service, they do represent an effective and radical means of rapidly establishing equality considerations on the public policy agenda.

A review of the context of policy processes in planning may therefore help indicate the most appropriate means of effecting widespread change. Under such a perspective, the centralized nature of the British Planning system could be exploited by issuing strong central planning guidance on the issue of cultural pluralism as a way of influencing techno-rational and bureaucratic-legal processes (as suggested by Thomas \& Krishnarayan, 1994). Similarly, the context of Sweden described by Khakee and Thomas (1995) would suggest that in the absence of a broader political debate around racial disadvantage, an effective initiative would be to first 
encourage the planning profession itself to highlight the potential for discrimination to its members and to take a more comprehensive and principled stance against discrimination.

\section{Conclusion}

For over 17 years there has been strong evidence from England, Wales and Scotland that most local authorities have not recognized the possibility that racial disadvantage may be accentuated through the planning process. In the light of the findings from Northern Ireland, it can be seen that this is true for the whole of the UK, despite the very different context for planning across the country. This leads to a number of conclusions that are relevant to the debate of planning and multiculturalism in Europe. Drawing on the work of Thomas and Krishnarayan (1994) the concept of 'policy processes' is seen to be an effective way of analysing how Black and ethnic minority groups may become disadvantaged in planning. However, it has been suggested here that while their research provides a framework for understanding how disadvantage arises in planning, the context for such processes needs to be fully understood to explain more local responses to this issue. In the case of Northern Ireland, the political circumstances governing group relations and the planning profession's response to the broader political conflict has been shown to be critical in constraining policy processes that may result in more accommodation of cultural pluralism and helps identify those processes through which change can be more easily implemented.

\section{Acknowledgements}

I am indebted to the anonymous referees who made a number of very helpful suggestions on an earlier draft.

\section{Notes}

1. See CRE/RTPI, 1983; Krishnarayan \& Thomas, 1993; Loftman \& Beazley, 1998.

2. Throughout this paper the term 'ethnic minority' will be used to refer to people of cultures other than those of an Anglo-Irish tradition such as Black and Asian groups. The Protestant and Catholic communities in Northern Ireland are regarded by some as having ethnic identities, but will not be the main focus of discussion here (see Brewer, 1992).

3. Thomas and Krishnarayan's analysis is based on the categorization by Healey et al. (1988) in which policy processes in public administration are seen as being bureaucratic-legal, technorational, semi-judical, politicorational and consultative.

4. This increase may be partly explained by more effective recording on the part of the police and a greater willingness to report such incidents on the part of ethnic minorities.

5. This Direct Rule lasted until December 1999 when there was devolution as part of the peace process. However, a failure to agree on decommissioning of arms resulted in the suspension of the new Assembly in February 2000. At the time of writing (late May 2000) the Assembly has been reconvened.

6. The political structures set up as part of the peace process has established a new department of Regional Development that has taken on a number of planning related functions.

7. Hainsworth (1998) reviews the positions of the political parties in relations to race relations and suggests that “... politicians who are so conscious of defending their own group and historico-cultural identity are not prepared to accept the same rights for others."

8. In terms of the perspective taken by Thomas and Krishnarayan (1994), this suggests that the technorational process would be the dominant one for addressing ethnic minority needs in planning. 
9. For example the Traveller Movement (NI), Chinese Welfare Association, Northern Ireland Committee for Ethnic Minorities and the Commission for Racial Equality (NI).

10. The Chinese Welfare Association have been unable to establish a community centre, sheltered housing scheme and burial ground in Belfast because of local opposition and lack of appropriate sites.

\section{References}

Blackman, T. (1991) Planning Belfast. Aldershot: Avebury.

BoAL, F. W. (1996) Integration and division: sharing and segregation in Belfast, Planning Practice and Research, 11(2), pp. 151-158.

Bost, F. W. (1999) From undivided cities to undivided cities: assimilation to ethnic cleansing, Housing Studies, 14(5), pp. 585-600.

Bollens, S. A. (1999) Urban Peace-Building in Divided Societies: Belfast and Fohannesburg. Boulder, CO: Westview Press.

Brewer, J. D. (1992) Sectarianism and racism, Ethnic and Racial Studies, 15(3), pp. 352-64.

Brewer, J. D. and Dowds, L. (1996) Race, ethnicity and prejudice in Northern Ireland, in R. Breen, P. Devine and L. Dowds (Eds) Social Attitudes in Northern Ireland, Chapter 5. Belfast: Appletree Press.

Castles, S. and Miller, M. (1993) The Age of Migration, London: Macmillan.

Commission for Racial Equality/Royal Town Planning Institute (CRE/RTPI) (1983) Planning for a Multi-racial Britain. London: CRE.

Connolly, P. and Keenan, M. (2000) Racial Attitudes and Prejudice in Northern Ireland. Belfast: NISRA.

Davies, L. (1993) Planning for Black People and Ethnic Minorities: A Study of the Southwest Region, RTPI, SW Branch.

Department of the Environment (Northern Ireland) (DoE(NI)) (1998) Shaping Our Future, Draft Regional Strategic Framework, Belfast: HMSO.

Department of Environment, Transport and the Regions (DeTR) (1998) Modernising Planning: A Policy Statement by the Minister for the Regions, Regeneration and Planning. London: DETR.

Donnan, H. and O'Brien, M. (1997) Because you stick out, you stand out: perceptions of prejudice among Northern Ireland's Pakistanis, in P. Hainsworth (Ed.) Divided Society: Ethnic Minorities and Racism in Northern Ireland, Chapter 10. London: Pluto Press.

Greater London Council (GLC) (1985) Race and Planning Guidelines, London: GLC.

ELLIS, G. (2000a) Planning and 'race' in Northern Ireland, in W. J. V. NeILL (Ed.) Urban Planning and Cultural Pluralism, pp. 63-73. Belfast: RTPI (Northern Branch).

ELLIS, G. (2000b) Addressing inequality: planning in Northern Ireland, International Planning Studies, 5(3), pp. $345-364$.

Hainsworth, P. (1998) Politics, racism and ethnicity in Northern Ireland, in P. Hainsworth (Ed.) Divided Society: Ethnic Minorities and Racism in Northern Ireland, Chapter 2. London: Pluto Press.

Healey, P. (1990) Policy processes in planning, Policy and Politics, 18(1), pp. 91-103.

Healey, P., McNamara, P., Elson, M. and Doak, J. (1988) Land Use Planning and the Mediation of Urban Change. Cambridge: Cambridge University Press.

Home Office (1999) Stephen Lawerence Inquiry: Home Secretary's Action Plan. London: HMSO.

Hudson, B. M. (1979) Comparison of current planning theories: counterparts and contradictions, fournal of the American Planning Association, 45(4), pp. 387-398.

Irwin, G. (1997) The Indian community in Northern Ireland, in P. HaInsworth (Ed.) Divided Society: Ethnic Minorities and Racism in Northern Ireland, Chapter 9. London: Pluto Press.

Irwin, G. and Dunn, S. (1996) Ethnic Minorities in Northern Ireland. Coleraine: Centre for the Study of Conflict, University of Ulster.

Khakee, A. and Thomas, H. (1995) Ethnic minorities and the planning system in Britain and Sweden, European Planning Studies, 3(4), pp. 489-510.

Krishnarayan, V. and Thomas, H. (1993) Ethnic Minorities and the Planning System, London: RTPI.

Loftman, P. and Beazley, M. (1998) Race, Equality and Planning, London: LGA.

MaEldowney, J. M., et al. (1997) Beyond Land Use Planning: New Approaches to Community Participation in Strategic Planning for the Belfast City Region. Paper to the XI AESOP Congress, Nijmegen, Netherlands, May. 
MacPherson, W. (1999) The Stephen Laurence Inquiry. Report of an Inquiry by Sir William Macpherson (Cm 4262-1). London: HMSO.

McVeigh, R. (1992) The specificity of Irish racism, Race and Class, 33(4), pp. 31-45.

McVeigh, R. (1997) Ethnic minorities and the numbers game, fust News, 12(3).

MCVeigh, R. (1998) “There's no racism because there's no Black people here": Racism and anti-racism in Northern Ireland, in P. Hainsworth (Ed.) Divided Society: Ethnic Minorities and Racism in Northern Ireland, Chapter 1. London: Pluto Press.

Mann-Kler, D. (1997) Out of the Shadowes: An Action Research Report into Families, Racism and Exclusion in Northern Ireland. Barnardos, Belfast Traveller Education and Development Group, Committee for the Administration of Justice, Chinese Welfare Association, Craigavon Women and Children's Association, Indian Community Centre, NI Council for Ethnic Minorities and Save the Children, Belfast.

Marger, M. (1989a) Factors of structural pluralism in multiethnic societies: a comparative case study, International Journal of Group Tensions, 19(1), pp. 52-67.

Marger, M. (1989b) Asians in the Northern Ireland economy, New Community, 15(1), pp. 203-210.

Mason, C. (1998) Health issues and ethnic minorities in Northern Ireland, in P. Hainsworth (Ed.) Divided Society: Ethnic Minorities and Racism in Northern Ireland, Chapter 5. London: Pluto Press.

MiLes, R. (1987) Class relations and racism in Britain in the 1980s, Revue Européene des Migrations Internationale, 3(1-2), pp. 223-228.

Molloy, S. (1998) Accommodating Nomadism. Belfast: Traveller Movement (NI).

Munt, I. (1991) Black organisations, planning and access to premises, New Community, 17, pp. 583-602.

NeiLl, W. J. V. (1998) Place visions and representational landscapes: 'reading' Stormont in Belfast and the Palast der Republik in Berlin, Planning Practice and Research, 13(4), pp. 386-406.

NeILL, W. J. V. (1999) Whose city? Can a place vision for Belfast avoid the issue of identity? European Planning Studies, 7(3), pp. 269-281.

Noonan, P. (1998) Pathologisation and resistance: Travellers, Nomadism and the State, in P. Hainsworth (Ed.) Divided Society: Ethnic Minorities and Racism in Northern Ireland, Chapter 8. London: Pluto Press.

Northern Ireland Gouncil for Ethnic Minorities (NICEM) (1999) Estimated Black and Ethnic Minority Population in Northern Ireland, Belfast: NICEM.

O'Brion, E. (1997) Living between green and orange: ethnic minorities in Northern Ireland, in E. Crowley and J. MacLaughlin (Eds.) Under the Belly of the Tiger, Class, Race Identify and Culture in the Global Ireland. Dublin: Irish Reporter Publications.

Office of Population Censuses and Surveys (OPCS) (1993) 1991 Census Report for Great Britain. London: HMSO.

Planning Service (1996) Framework Document. Belfast: Planning Service.

Quadeer, M. A. (1997) Pluralistic planning for multicultural cities: the Canadian practice, fournal of the American Planning Association, 63(4), pp. 481-494.

Reade, E. (1987) British Town and Country Planning. Milton Keynes: Open University Press.

Royal Town Planning Institute (RTPI) (1996) Planning Authorities and Racist Representations, London: RTPI.

Skellington, R. and Morris, P. (1996) Race in Britain Today, 2nd edn. London: Sage.

Thomas, H. (1994a) Race, Equality and Planning, Aldershot: Avebury.

Thomas, H. (1994b) The new right: 'race' and planning in Britain in the 1980s and 1990s, Planning Practice \& Research, 9(4), pp. 353-366.

Thomas, H. and Krishnarayan, V. (1994) 'Race' disadvantage and policy process in British planning, Environment and Planning A, 26(12), pp. 1891-1910.

Thompson, R. (1987) Is fastest best? The case of development control, The Planner, 73(9), pp. 11-15.

Trimbos, J. (1997) Planning in Northern Ireland, Journal of Planning and Environmental Law, October, pp. 904-907.

Watson, A. and Knight, E. (1997) Race and ethnicity in Northern Ireland: the Chinese community, in: P. Hainsworth (Ed.) Divided Society: Ethnic Minorities and Racism in Northern Ireland, Chapter 7. London: Pluto Press.

White, C. (1997) Race discrimination, in B. Dickson (Ed.) Civil Liberties in Northern Ireland. Belfast: CAJ, Appletree Press. 